CrossMark $\leftarrow$ click for updates

Cite this: Org. Biomol. Chem., 2017, 15, 1321

Received 15th December 2016, Accepted 9th January 2017

DOI: $10.1039 / c 6 o b 02745 h$

rsc.li/obc

\section{Reversal of the sense of enantioselectivity between 1- and 2-aza[6]helicenes used as chiral inducers of asymmetric autocatalysis $\uparrow$}

\author{
Arimasa Matsumoto, ${ }^{\text {a,b }}$ Kento Yonemitsu, ${ }^{a}$ Hanae Ozaki, ${ }^{a}$ Jiři Míšek, ${ }^{c}$ Ivo Starý, ${ }^{c}$ \\ Irena G. Stará*c and Kenso Soai*a,b
}

\begin{abstract}
Reversal of the sense of enantioselectivity was observed between 1-aza[6]helicene 2 and 2-aza[6]helicene 3 employed as chiral inducers of asymmetric autocatalysis of pyrimidyl alkanol. In the presence of $(P)-(+)-1$-aza[6]helicene 2, the reaction of pyrimidine5-carbaldehyde 1 with diisopropylzinc afforded, in conjunction with asymmetric autocatalysis, (S)-pyrimidyl alkanol 4 with high ee. Surprisingly, the reaction in the presence of $(P)-(+)-2$-aza[6] helicene 3 gave the opposite enantiomer of $(R)$-alkanol 4 with high ee. In the same manner, $(M)-(-)-2$ and $(M)-(-)-3$ afforded $(R)-$ and (S)-alkanol 4, respectively. The sense of enantioselectivity is controlled not only by the helicity of the azahelicene derivatives but also by the position of the nitrogen atom.
\end{abstract}

Enormous progress has been achieved in the absolute stereochemistry control of enantioselective catalytic organic reactions within the last few decades. Although various types of chirality inducers have systematically been explored, small helical organocatalysts or metal complexes bearing helical ligands have rarely been used in enantioselective catalysis until recently. ${ }^{1}$ Stimulated by a successful development of diverse synthetic methodologies for the preparation of functionalized (hetero)helicenes in a racemic or enantiopure form, ${ }^{2,3}$ their application to enantioselective catalysis has nowadays been attracting considerable attention and this field of chiroscience is rapidly expanding. Within the last few years, new helicene-derived chiral inducers have been prepared and their high efficiency in chirality transfer (or reactivity) in diverse fields of catalysis was demonstrated by Cauteruccio et al., ${ }^{4}$ Cauteruccio, Benaglia et al. ${ }^{5}$ Licandro, Hashmi et al., ${ }^{6}$ Marinetti, Voituriez et al., ${ }^{7}$ Suemune, Usui et al., ${ }^{8}$ Tsujihara,

${ }^{a}$ Department of Applied Chemistry, Tokyo University of Science, Kagurazaka, Shinjuku-ku, Tokyo, 162-8601 Japan. E-mail: soai@rs.kagu.tus.ac.jp

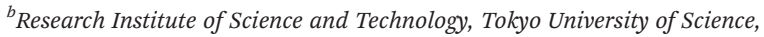
Kagurazaka, Shinjuku-ku, Tokyo, 162-8601 Japan

${ }^{c}$ Institute of Organic Chemistry and Biochemistry, Czech Academy of Sciences, Flemingovo nám. 2, 16610 Prague 6, Czech Republic.

E-mail: ivo.stary@uochb.cas.cz, stara@uochb.cas.cz

†CCDC 1521681 and 1521682. For crystallographic data in CIF or other electronic format see DOI: 10.1039/c6ob02745h
Kawano et $a l .{ }^{9}$ and Stará, Starý et al. ${ }^{10}$ However, to the best of our knowledge, only a few studies on azahelicenes (or their simple derivatives) in enantioselective catalysis have so far been carried out by Carbery et al., ${ }^{11}$ Stará, Starý et al. ${ }^{12}$ and Takenaka et al. ${ }^{13}$

In the realm of enantioselective catalysis, the Soai reaction $^{14-16}$ possesses a prominent position as it exhibits a unique chirality amplification through the asymmetric autocatalysis. Chirality inducers of a fascinating diversity (ranging from circularly polarized light ${ }^{17}$ to isotopically chiral compounds $^{18}$ and chiral inorganic materials ${ }^{19}$ ) were found to control effectively the absolute configuration of enantiopure or highly enantioenriched 5-pyrimidyl alkanol as the product of diisopropylzinc addition to the corresponding pyrimidine5 -carbaldehyde. Intriguingly, the influence of helically chiral (hetero)helicenes on the stereochemical outcome of this reaction has already been examined to find a high level of chirality transfer (Scheme 1). ${ }^{20}$ Regardless of the absence/presence of
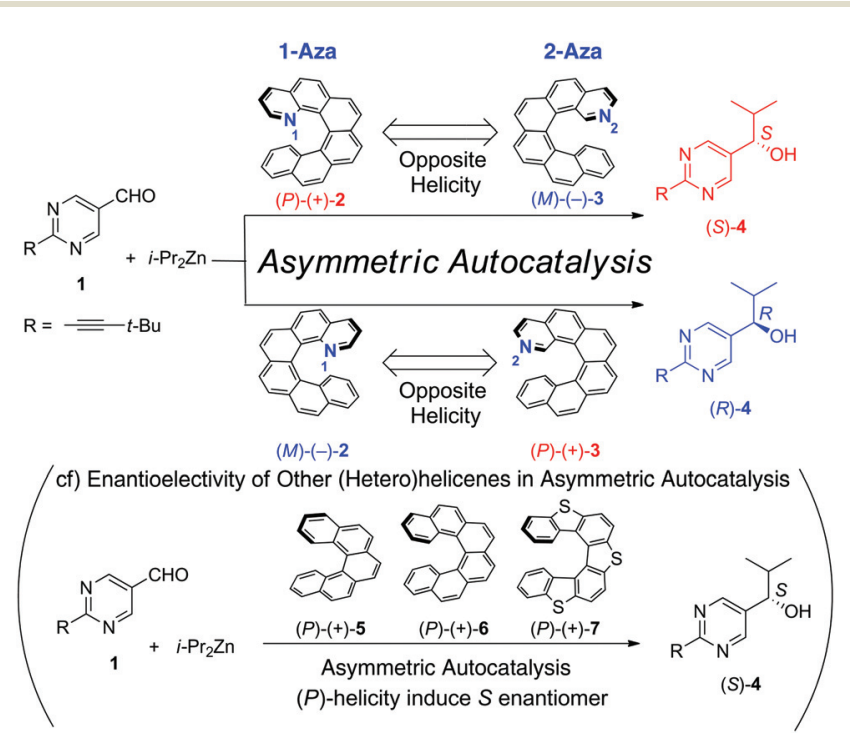

Scheme 1 Reversal of enantioselectivity by the positions of the nitrogen atoms of 1- and 2-aza[6]helicenes. 
heteroatoms and the length of the backbone, the use of the $(P)-(+)$ enantiomers of [5]helicene 5, [6]helicene 6 or tetrathia [7]helicenes 7 in catalytic amounts resulted uniformly in the formation of $(S)-(-)-4$. Complementarily, the respective $(M)-(-)$ helicene enantiomers induced the opposite chirality of $(R)-(+)-\mathbf{4}$. Although different mechanisms of the chirality transfer were proposed (a noncovalent interaction between the helical hydrocarbons 5 or 6 and pyrimidine-5-carbaldehyde 1 to form a chiral aldehyde complex ${ }^{20 a}$ or, alternatively, coordination of diisopropylzinc to sulfur atoms of thiahelicenes 7 to generate a chiral active zinc species ${ }^{20 b}$ ), a pivotal role of the helicity of the chirality inducer in the enantioselective reaction was experimentally demonstrated. Interestingly, the enantioselective addition of diethylzinc to benzaldehyde and its derivatives under catalysis by $(P, P)-(+)$-bis[5]helicenediol was pioneered by Katz et $a .^{21}$ They observed the good ee's and predominant formation of $(S)-(-)$-1-phenylpropanol (and its $o$-chloro, $p$-chloro and $p$-methoxy derivatives of the same absolute configuration) in agreement with the aforementioned results by Soai et al. Thus, as so far found, the use of $(P)$-helicene as the chirality inducer in the asymmetric addition of dialkylzinc to (hetero) aromatic aldehydes leads generally to the $(S)$-configuration of the corresponding (hetero)aryl alkanol while $(M)$-helicene favors the formation of $(R)$-(hetero)aryl alkanol.

Herein, we report on the use of the enantioenriched $(P)-(+) /(M)-(-)$-1-aza[6]helicene $2^{22}$ and 2-aza[6]helicene $3^{22}$ (Scheme 1) as chirality inducers in the enantioselective addition of diisopropylzinc (i- $\left.\mathrm{Pr}_{2} \mathrm{Zn}\right)$ to pyrimidine-5-carbaldehyde 1 to demonstrate that the absolute configuration of the resulting pyrimidyl alkanol $\mathbf{4}$ is controlled not only by the helicity of the azahelicene derivatives but also the position of the nitrogen atom in them.

Both 1-aza[6]helicene 2 and 2-aza[6]helicene 3 were synthesized in the racemic form by employing $[2+2+2]$ cycloisomerization of triynes to form their helical backbone. ${ }^{22}$ Optically pure $(M)$ and $(P)$ enantiomers were obtained by resolution of the corresponding racemates by co-crystallization with (+)-O, $O^{\prime}$-dibenzoyl- $d$-tartaric acid or HPLC on a Chiralcel OD-H column (heptane/2-propanol 3:1). The helicity of the resolved enantiomers was unequivocally assigned by comparing their ECD spectra with that of $(P)-(+)-[6]$ helicene ${ }^{23}$ whose helicity is known. ${ }^{24}$ Furthermore, the absolute helicities of both 1- and 2-aza[6]helicene were confirmed by single crystal $\mathrm{X}$-ray diffraction analysis of enantiopure crystals with a $\mathrm{Cu} \mathrm{K} \alpha$ X-ray source.t

The results of asymmetric autocatalysis initiated by enantioenriched 1-aza[6]helicenes 2 or 2 -aza[6]helicenes 3 are summarized in Table $1 . \S$ When pyrimidine-5-carbaldehyde 1 was reacted with i- $\mathrm{Pr}_{2} \mathrm{Zn}$ using $(P)-(+)-1$-aza[6] helicene 2 with $>99 \%$ ee as the chiral inducer, $(S)-(-)$-pyrimidyl alkanol 4 with $99 \%$ ee was obtained (Table 1, entry 1). On the other hand, the presence of $(M)-(-)-2$ with $99 \%$ ee gave the opposite enantiomer of $(R)-(+)$-alkanol 4 with $97 \%$ ee (entry 2 ). The ee of the products was amplified over $>99.5 \%$ by additional rounds of asymmetric autocatalysis cycles. ${ }^{14 b}$ The correlation between the absolute configurations of 1-aza[6]helicene 2 and the alkanol 4 is
Table 1 Asymmetric autocatalysis initiated by enantioenriched 1-aza[6] helicene 2 and 2 -aza[6]helicene 3

\begin{tabular}{|c|c|c|c|c|c|}
\hline \multirow[b]{2}{*}{ Entry } & \multicolumn{2}{|c|}{$\begin{array}{l}\text { 1-Aza[6] helicene } 2^{a} \\
\text { or } 2 \text {-aza[6] helicene } 3^{b}\end{array}$} & \multicolumn{3}{|c|}{ Pyrimidyl alkanol 4} \\
\hline & & ee $[\%]$ & Yield [\%] & $\mathrm{ee}^{c}[\%]$ & Config. \\
\hline 1 & $(P)-(+)-2$ & $>99$ & 89 & $99(99.5)^{d}$ & $S$ \\
\hline 2 & $(M)-(-)-2$ & $>99$ & 89 & $97(99.5)^{d}$ & $R$ \\
\hline 3 & $(P)-(+)-2$ & $>99$ & 85 & 77 & $S$ \\
\hline 4 & $(M)-(-)-2$ & $>99$ & 90 & 92 & $R$ \\
\hline 5 & $(P)-(+)-2$ & 33 & 91 & 99 & $S$ \\
\hline 6 & $(M)-(-)-2$ & 30 & 94 & 96 & $R$ \\
\hline 7 & $(P)-(+)-3$ & $>99$ & 88 & 93 & $R$ \\
\hline 8 & $(M)-(-)-3$ & $>99$ & 84 & 97 & $S$ \\
\hline 9 & $(P)-(+)-3$ & $>99$ & 72 & 91 & $R$ \\
\hline 10 & $(M)-(-)-3$ & $>99$ & 87 & 89 & $S$ \\
\hline 11 & $(P)-(+)-3$ & $>99$ & 73 & 91 & $R$ \\
\hline 12 & $(M)-(-)-3$ & $>99$ & 74 & 93 & $S$ \\
\hline
\end{tabular}

${ }^{a}$ Reaction conditions: molar ratio $1: 2: \mathrm{i}-\mathrm{Pr}_{2} \mathrm{Zn}=1: 0.4: 6.7$ in toluene $0{ }^{\circ} \mathrm{C}$, additional aldehyde 1 (6.7 equiv. and 26.7 equiv.) and $\mathrm{i}-\mathrm{Pr}_{2} \mathrm{Zn}$ (20 equiv. and 53.3 equiv.) were added stepwise. ${ }^{b}$ Molar ratio reaction conditions: $1: 3: \mathrm{i}-\mathrm{Pr}_{2} \mathrm{Zn}=1: 0.2: 6.7$ in toluene $0{ }^{\circ} \mathrm{C}$, additional aldehyde 1 (6.7 equiv. and 26.7 equiv.) and $\mathrm{i}-\mathrm{Pr}_{2} \mathrm{Zn}$ (20 equiv. and 53.3 equiv.) were added stepwise. ${ }^{c}$ The ee value was determined by HPLC. ${ }^{d}$ After additional rounds of asymmetric autocatalysis. ${ }^{14 b}$

reproducible (entries 3 and 4). Even when the chiral initiators of $(P)-(+)-$ and $(M)-(-)-2$ of a low enantioenrichment $(33 \%$ ee and $30 \%$ ee, respectively) were employed, the same correlation of absolute configurations was manifested by the formation of $(S)-(-)$ - and $(R)-(+)$-alkanol 4 with $99 \%$ and $96 \%$ ee, respectively. This selectivity of the chiral 1-aza[6] helicene 2 as a chiral inducer of asymmetric autocatalysis, i.e., $(P)-(+)-2$ affords $(S)-(-)$-alkanol 4, is constant with the stereocontrol by $(P)-(+)-[5]$ helicene 5, $(P)-(+)-[6]$ helicene 6 and $(P)-(+)-$ thia[7] helicene 7 affording also $(S)$-(-)-alkanol 4.

Unexpected results, however, were obtained when 2-aza[6] helicene 3 was used as the chiral inducer. In the presence of $(P)-(+)-3,(R)-(+)$-alkanol 4 with $93 \%$ ee was formed instead of $(S)-(-)-4$ (entry 7$)$. The opposite enantiomer $(M)-(-)-3$ gave (S)-(-)-4 with $97 \%$ ee (entry 8) and, as shown in entries 9-12, these intriguing opposite enantioselectivity correlations were reproducible. Although the actual mechanism of the chirality transfer by helicenes in asymmetric autocatalysis is not clear so far, this enantioselectivity reversal induced by 2 -aza[6] helicene 3 in contrast to other helicenes might be caused by the presence of an accessible coordinative nitrogen atom. As expected from the structure of 3 , the steric hindrance around the 2-position of [6]helicene is much smaller than that around the 1-position. Furthermore, from the result of an X-ray crystallography analysis, 2-aza[6]helicene 3 has the larger helicity pitch than 1-aza[6] helicene 2 due to the steric repulsion between the $\mathrm{C}-\mathrm{H}$ units in the 1 - and 16 -positions. ${ }^{22}$ * Accordingly, 2-aza[6] helicene 3 is proposed to be coordinated to alkyl zinc. It is worth noting that an interaction between the pyrimidine ring and zinc reagent was already considered to play a key role in the mechanism of the asymmetric autocatalysis reaction. ${ }^{25}$ 


\section{Conclusions}

In conclusion, we have demonstrated the asymmetric autocatalysis of pyrimidyl alkanol 4 with chiral 1- and 2-aza[6] helicenes 2 and 3. The absolute stereochemistry of the alkanol product can be controlled by the helicity of the used azahelicenes. Furthermore, we have confirmed the helicity of the enantiopure 1-aza[6]helicene 2 and 2-aza[6] helicene 3 by ECD spectra and X-ray single crystal analysis. We have found that the correlation between the helicity and enantioselectivity in asymmetric autocatalysis depends not only on the helicity of the chirality inducer but also on the position of the nitrogen atom. The mechanism of the chirality transfer remains still unclear but this unusual stereoselectivity reversal represents an interesting phenomenon that might be applied to asymmetric autocatalysis.

\section{Acknowledgements}

This work was supported in part by the $\mathrm{T}$ Grant-in-Aid for Scientific Research from the Promotion of Science (JSPS KAKENHI Grant Numbers 26810026 \& 15H03781), the MEXT-Supported Program for the Strategic Research Foundation at Private Universities, 2012-2016, Czech Science Foundation (Reg. No. 14-29667S) and the Institute of Organic Chemistry and Biochemistry, Czech Academy of Sciences (RVO: 61388963). I. S. acknowledges the support by the Japan Society for the Promotion of Science for JSPS Fellowship. We are grateful to Miloš Tichý for the resolution of racemic azahelicenes into individual enantiomers.

\section{Notes and references}

\$X-ray diffraction analysis was performed using a Rigaku R-AXIS RAPID II imaging plate system with a Cu rotating anode X-ray source. The Flack parameter was determined by using the Parsons quotients method (Parsons, Flack and Wagner, Acta Crystallogr., Sect. B: Struct. Sci., 2013, 69, 249-259) with SH. Due to the obtained crystal size and quality, the deviation of Flack parameters is slightly high $(-0.1(4)$ for $(M)-(-)-2$ and $0.1(4)$ for $(P)-(+)-3)$. However, considering the good accordance of the ECD spectrum with other helicene derivatives we conclude that the assignment of the absolute structure is unequivocal. Crystallographic data have been deposited with the Cambridge Crystallographic Data Centre as supplementary publication no. CCDC 1521682 for $(M)-(-)-2$ and CCDC 1521681 for $(P)-(+)-3$.

$\S$ Typical experimental procedure (Table 1, entry 1): 1-Aza[6]helicene $(P)-(+)-2$ $\left(1.97 \mathrm{mg}, 6.0 \times 10^{-3} \mathrm{mmol}, 0.4\right.$ equiv.) and pyrimidine-5-carbaldehyde $\mathbf{1}(2.8 \mathrm{mg}$, $0.015 \mathrm{mmol}, 1$ equiv.) were dissolved in $0.025 \mathrm{~mL}$ of toluene under an argon atmosphere. Then, diisopropylzinc in toluene $(1.0 \mathrm{M}, 0.10 \mathrm{~mL}, 0.10 \mathrm{mmol}$, 6.7 equiv.) was added dropwise over $2 \mathrm{~h}$ at $0{ }^{\circ} \mathrm{C}$. After stirring overnight at $0{ }^{\circ} \mathrm{C}$, one-pot scale up of asymmetric autocatalysis was performed by adding toluene $(0.1 \mathrm{~mL})$ and $1 \mathrm{M}$ diisopropylzinc toluene solution $(0.3 \mathrm{~mL}, 0.3 \mathrm{mmol})$ followed by the dropwise addition of aldehyde $1(18.8 \mathrm{mg}, 0.1 \mathrm{mmol})$ in toluene $(0.5 \mathrm{~mL})$ over $2 \mathrm{~h}$. After $2 \mathrm{~h}$ stirring, the additional scale up of asymmetric autocatalysis was performed in the same way with toluene $(3.5 \mathrm{~mL}), 1 \mathrm{M}$ diisopropylzinc ( $0.8 \mathrm{~mL}, 0.8 \mathrm{mmol})$, and aldehyde $\mathbf{1}(75.3 \mathrm{mg}, 0.4 \mathrm{mmol})$ in toluene $(2 \mathrm{~mL})$. The reaction mixture was stirred overnight, and the reaction was quenched using a mixture of sat. aq. $\mathrm{NH}_{4} \mathrm{Cl}$ and $30 \%$ aq. $\mathrm{NH}_{3}(2 / 1, \mathrm{v} / \mathrm{v}, 10 \mathrm{~mL})$. The resulting mixture was extracted with AcOEt $(3 \times)$. The combined organic layers were dried over anhydrous $\mathrm{Na}_{2} \mathrm{SO}_{4}$ and the volatiles were removed under reduced pressure.
Purification of the residue using silica gel column chromatography (eluent: hexane/EtOAc $=2 / 1)$ gave $(S)-(-)-5$-pyrimidyl 4 (106.1 mg, 89\% yield) with $99 \%$ ee. The ee value was determined by HPLC analysis on a chiral stationary phase (Daicel Chiralpak IB: $4.6 \mathrm{~mm} \times 250 \mathrm{~mm}, 254 \mathrm{~nm}$ UV detector, RT, 5\% 2-propanol

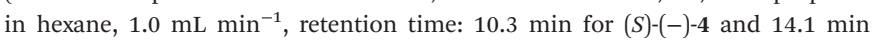
for $(R)-(+)-4)$.

1 (a) M. J. Narcis and N. Takenaka, Eur. J. Org. Chem., 2014, 21-34; (b) P. Aillard, A. Voituriez and A. Marinetti, Dalton Trans., 2014, 43, 15263-15278; (c) N. Saleh, C. Shen and J. Crassous, Chem. Sci., 2014, 5, 3680-3694.

2 For recent reviews, see: (a) I. G. Stará and I. Starý, in Science of Synthesis, ed. J. S. Siegel and Y. Tobe, Thieme, Stuttgart, 2010, vol. 45b, pp. 885-953; (b) Y. Shen and C.-F. Chen, Chem. Rev., 2011, 112, 1463-1535; (c) M. Gingras, Chem. Soc. Rev., 2013, 42, 968-1006; (d) M. Gingras, G. Félix and R. Peresutti, Chem. Soc. Rev., 2013, 42, 1007-1050; (e) M. Gingras, Chem. Soc. Rev., 2013, 42, 1051-1095; (f) K. Tanaka, in Transition-Metal-Mediated Aromatic Ring Construction, ed. K. Tanaka, Wiley, Hoboken, 2013, pp. 281-298; $(g)$ A. Urbano and M. C. Carreño, Org. Biomol. Chem., 2013, 11, 699-708; (h) J. Bosson, J. Gouin and J. Lacour, Chem. Soc. Rev., 2014, 43, 2824-2840; (i) N. Saleh, C. Shen and J. Crassous, Chem. Sci., 2014, 5, 3680-3694.

3 (a) Y. Kimura, N. Fukawa, Y. Miyauchi, K. Noguchi and K. Tanaka, Angew. Chem., Int. Ed., 2014, 53, 8480-8483; (b) T. Shibata, T. Uchiyama, Y. Yoshinami, S. Takayasu, K. Tsuchikama and K. Endo, Chem. Commun., 2012, 48, 1311-1313; (c) H. Oyama, M. Akiyama, K. Nakano, M. Naito, K. Nobusawa and K. Nozaki, Org. Lett., 2016, 18, 3654-3657; (d) M. Yamaguchi, M. Arisawa, M. Shigeno and N. Saito, Bull. Chem. Soc. Jpn., 2016, 89, 1145-1169.

4 D. Dova, L. Viglianti, P. R. Mussini, S. Prager, A. Dreuw, A. Voituriez, E. Licandro and S. Cauteruccio, Asian J. Org. Chem., 2016, 5, 537-549.

5 S. Cauteruccio, D. Dova, M. Benaglia, A. Genoni, M. Orlandi and E. Licandro, Eur. J. Org. Chem., 2014, 26942702.

6 S. Cauteruccio, A. Loos, A. Bossi, M. C. B. Jaimes, D. Dova, F. Rominger, S. Prager, A. Dreuw, E. Licandro and A. S. K. Hashmi, Inorg. Chem., 2013, 52, 7995-8004.

7 (a) K. Yavari, P. Aillard, Y. Zhang, F. Nuter, P. Retailleau, A. Voituriez and A. Marinetti, Angew. Chem., Int. Ed., 2014, 53, 861-865; (b) M. Gicquel, Y. Zhang, P. Aillard, P. Retailleau, A. Voituriez and A. Marinetti, Angew. Chem., Int. Ed., 2015, 54, 5470-5473; (c) P. Aillard, P. Retailleau, A. Voituriez and A. Marinetti, Chem. - Eur. J., 2015, 21, 11989-11993; (d) P. Aillard, D. Dova, V. Magné, P. Retailleau, S. Cauteruccio, E. Licandro, A. Voituriez and A. Marinetti, Chem. Commun., 2016, 52, 1098410987.

8 K. Yamamoto, T. Shimizu, K. Igawa, K. Tomooka, G. Hirai, H. Suemune and K. Usui, Sci. Rep., 2016, 6, 36211.

9 T. Tsujihara, N. Inada-Nozaki, T. Takehara, D.-Y. Zhou, T. Suzuki and T. Kawano, Eur. J. Org. Chem., 2016, 4948-4952. 
10 I. G. Sánchez, M. Šámal, J. Nejedlý, M. Karras, J. Klívar, J. Rybáček, M. Buděšínský, L. Bednárová, B. Seidlerová, I. G. Stará and I. Starý, submitted.

11 (a) M. R. Crittall, H. S. Rzepa and D. R. Carbery, Org. Lett., 2011, 13, 1250-1253; (b) M. R. Crittall, N. W. G. Fairhurst and D. R. Carbery, Chem. Commun., 2012, 48, 11181-11183.

12 M. Šámal, J. Míšek, I. G. Stará and I. Starý, Collect. Czech. Chem. Commun., 2009, 74, 1151-1159.

13 (a) N. Takenaka, R. S. Sarangthem and B. Captain, Angew. Chem., Int. Ed., 2008, 47, 9708-9710; (b) J. Chen and N. Takenaka, Chem. - Eur. J., 2009, 15, 7268-7276; (c) N. Takenaka, J. Chen, B. Captain, R. S. Sarangthem and A. Chandrakumar, J. Am. Chem. Soc., 2010, 132, 4536-4537; (d) J. Chen, B. Captain and N. Takenaka, Org. Lett., 2011, 13, 1654-1657; (e) M. J. Narcis, D. J. Sprague, B. Captain and N. Takenaka, Org. Biomol. Chem., 2012, 10, 9134-9136.

14 (a) K. Soai, T. Shibata, H. Morioka and K. Choji, Nature, 1995, 378, 767-768; (b) I. Sato, H. Urabe, S. Ishiguro, T. Shibata and K. Soai, Angew. Chem., Int. Ed., 2003, 42, 315-317.

15 (a) K. Soai and T. Kawasaki, Top. Curr. Chem., 2008, 284, 1-31; (b) T. Kawasaki and K. Soai, Bull. Chem. Soc. Jpn., 2011, 84, 879-892; (c) K. Soai and T. Kawasaki, Asymmetric Autocatalysis - Discovery and State of The Art, in The Soai Reaction and Related Topic, ed. G. Palyi, C. Zicchi and L. Caglioti, Academia Nationale di Scienze Lettere e Arti Modena, Modena, Edizioni Artestampa, 2012, pp. 9-34; (d) T. Kawasaki and K. Soai, Isr. J. Chem., 2012, 52, 582590; (e) T. Kawasaki, I. Sato, H. Mineki, A. Matsumoto and K. Soai, Yuki Gosei Kagaku Kyokaishi (J. Synth. Org. Chem., Jpn.), 2013, 71, 109-123; (f) K. Soai and T. Kawasaki, Top. Organomet. Chem., 2013, 44, 261-279; $(g)$ K. Soai, T. Kawasaki and A. Matsumoto, Chem. Rec., 2014, 14, 70-83; (h) K. Soai, T. Kawasaki and A. Matsumoto, Acc. Chem. Res., 2014, 47, 3643-3654.

16 (a) M. Avalos, R. Babiano, P. Cintas, J. L. Jiménez and J. C. Palacios, Chem. Commun., 2000, 887-892; (b) D. G. Blackmond, Proc. Natl. Acad. Sci. U. S. A., 2004, 101, 5732-5736; (c) J. Podlech and T. Gehring, Angew. Chem., Int. Ed., 2005, 44, 5776-5777; (d) J. M. Brown, I. D. Gridnev and J. Klankermayer, Amplification of Chirality, in Topics in Current Chemistry, ed. K. Soai, 2008, vol. 284, pp. 35-65; (e) T. Gehring, M. Busch, M. Schlageter and D. Weingand, Chirality, 2010, 22, E173-E182; (f) B. Barabás, J. Tóth and G. Pályi, J. Math. Chem., 2010, 48, 457-489; $(g)$ G. Lente, Symmetry, 2010, 2, 767-798; (h) J.-C. Micheau, C. Coudret and T. Buhse, in The Soai Reaction and Related Topic, ed. G. Palyi, C. Zucchi and L. Caglioti, Accad. Nazl. Sci. Lett. Arti, Modena, Editioni Artestampa, 2012, pp. 169; (i) A. J. Bissette and S. P. Fletcher, Angew. Chem., Int. Ed., 2013, 52, 1280012826; (j) O. Fülöp and B. Barabás, J. Math. Chem., 2016, $54,10-17$.
17 (a) I. Sato, R. Sugie, Y. Matsueda, Y. Furumura and K. Soai, Angew. Chem., Int. Ed., 2004, 43, 4490-4492; (b) T. Kawasaki, M. Sato, S. Ishiguro, T. Saito, Y. Morishita, I. Sato, H. Nishino, Y. Inoue and K. Soai, J. Am. Chem. Soc., 2005, 127, 3274-3275.

18 (a) I. Sato, D. Omiya, T. Saito and K. Soai, J. Am. Chem. Soc., 2000, 122, 11739-11740; (b) T. Kawasaki, Y. Matsumura, T. Tsutsumi, K. Suzuki, M. Ito and K. Soai, Science, 2009, 324, 492-495; (c) T. Kawasaki, Y. Okano, E. Suzuki, S. Takano, S. Oji and K. Soai, Angew. Chem., Int. Ed., 2011, 50, 8131-8133; (d) A. Matsumoto, S. Oji, S. Takano, K. Tada, T. Kawasaki and K. Soai, Org. Biomol. Chem., 2013, 11, 2928-2931; (e) A. Matsumoto, H. Ozaki, S. Harada, K. Tada, T. Ayugase, H. Ozawa, T. Kawasaki and K. Soai, Angew. Chem., Int. Ed., 2016, 55, 15246-15249.

19 (a) K. Soai, S. Osanai, K. Kadowaki, S. Yonekubo, T. Shibata and I. Sato, J. Am. Chem. Soc., 1999, 121, 11235-11236; (b) I. Sato, K. Kadowaki and K. Soai, Angew. Chem., Int. Ed., 2000, 39, 1510-1512; (c) I. Sato, K. Kadowaki, H. Urabe, J. H. Jung, Y. Ono, S. Shinkai and K. Soai, Tetrahedron Lett., 2003, 44, 721-724; (d) H. Shindo, Y. Shirota, K. Niki, T. Kawasaki, K. Suzuki, Y. Araki, A. Matsumoto and K. Soai, Angew. Chem., Int. Ed., 2013, 52, 9135-9138; (e) A. Matsumoto, H. Ozawa, A. Inumaru and K. Soai, New J. Chem., 2015, 39, 6742-6745.

20 (a) I. Sato, R. Yamashima, K. Kadowaki, J. Yamamoto, T. Shibata and K. Soai, Angew. Chem., Int. Ed., 2001, 40, 1096-1098; (b) T. Kawasaki, K. Suzuki, E. Licandro, A. Bossi, S. Maiorana and K. Soai, Tetrahedron: Asymmetry, 2006, 17, 2050-2053.

21 S. D. Dreher, T. J. Katz, K.-C. Lam and A. L. Rheingold, J. Org. Chem., 2000, 65, 815-822.

22 J. Míšek, F. Teplý, I. G. Stará, M. Tichý, D. Šaman, I. Císařová, P. Vojtíšek and I. Starý, Angew. Chem., Int. Ed., 2008, 47, 3188-3191.

23 M. S. Newnam, R. S. Darlak and L. Tsai, J. Am. Chem. Soc., 1967, 89, 6191-6193.

24 D. A. Lightner, D. T. Hefelfinger, T. W. Powers, G. W. Frank and K. N. Trueblood, J. Am. Chem. Soc., 1972, 94, 34923497.

25 (a) I. Sato, D. Omiya, H. Igarashi, K. Kato, Y. Ogi, K. Tsukiyama and K. Soai, Tetrahedron: Asymmetry, 2003, 14, 975-979; (b) G. Ercolani and L. Schiaffino, J. Org. Chem., 2011, 76, 2619-2626; (c) T. Gehring, M. Quaranta, B. Odell, D. G. Blackmond and J. M. Brown, Angew. Chem., Int. Ed., 2012, 51, 9539-9542; (d) I. D. Gridnev and A. K. Vorobiev, ACS Catal., 2012, 2, 2137-2149; (e) A. Matsumoto, T. Abe, A. Hara, T. Tobita, T. Sasagawa, T. Kawasaki and K. Soai, Angew. Chem., Int. Ed., 2015, 54, 15218-15221; $(f)$ A. Matsumoto, S. Fujiwara, T. Abe, A. Hara, T. Tobita, T. Sasagawa, T. Kawasaki and K. Soai, Bull. Chem. Soc. Jpn., 2016, 1170-1177. 